\title{
Editorial
}

\section{Improvement of the Medical Education Situation in Sudan: Collegectomy is Not the Only Management Option} Mohamed Elhassan Abdalla*, Mohamed Hassan Taha

Medical Education Centre and College of Medicine, University of Sharjah, United Arab Emirates

Corresponding Author: melsayed@sharjah.ac.ae

Received 25 February 2020

Accepted 20 March 2020

Published 31 March 2020

Production and Hosting by

Knowledge E

CMohamed Elhassan

Abdalla. This article is distributed under the terms of the Creative Commons Attribution License, which permits unrestricted use and redistribution provided that the original author and source are credited.

Editor-in-Chief:

Prof. Mohammad A. M. Ibnouf

\section{Abstract}

Sudan witnessed an increase in the number of colleges of medicine after the higher education revolution in the early 1990s. Many authors writing about medical education, both in Sudan and across the world, have described a negative correlation between the increased number of medical colleges and the quality of education provided by those colleges. Many educational leaders in Sudan are calling for action to deal with the issues arising from this great expansion of medical colleges, with opinions varying from collegectomies (closure of the colleges) to merging colleges.

Several strategies have been implemented in Canada, Iran, the Philippines and South Africa to deal with similar situations. These have included college support such as funding or technical support, changing the colleges' educational strategies, modifying the curriculum, integrating (rather than merging) colleges, and collegectomies.

This paper outlines possible actions to be taken in response to the expansion of medical colleges in the Sudanese context. It explores the international experience with the situation in an attempt to augment the discussion with options that may help to improve medical education.

Key words: Collegectomy; medical education; Sudan; social accountability

\section{Introduction}

Sudan witnessed an increase in the number of colleges of medicine after the higher education revolution in the early 1990s. The total number rose from three to 66 , an increase equally split between public and private colleges [1, 2].

Many researchers in the field of medical education have described a negative correlation between this increased number and the quality of the education at these colleges [3, 4]. The situation in the United States that lead to the Flexner Report in 1910 is still shaping our thinking about medical education [5], although some authors have argued that there is no evidence of this correlation [6]. 
Those who are concerned by the negative impact on quality call for actions against colleges that do not meet educational standards [7], such as the immediate closure of these colleges (i.e., a collegectomy).

This paper outlines the possible actions to be taken to address the expansion of medical colleges in Sudan, expanding the discussion via the provision of a range of options that may help to improve medical education while avoiding 'collegectomies'.

\section{Colleges of Medicine and the Society}

In general, medical colleges hold a distinguished position within society and higher education systems because their mandate is to serve that society [8]. According to the definition of social accountability for medical colleges, 'society' includes the local society, the country, the region and the nation - provided the colleges' graduates engage in research and health services that serve any of these levels [9]. Based on this mandate, medical colleges are engaged in a highly dynamic relationship with society, using it and its institutions to teach and train students, provide direct and indirect health services, and draw on resources for research.

Based on the above, medical colleges have a social contract with the society they serve. This contract has an explicit duty to graduate safe doctors to practice in the society, especially if the students are recruited from the same area where the college is located. Incidentally, research has indicated that attracting students from or training of medical students in less developed regions leads to retention of a large number of graduates in those areas as part of the working health force in the future [10, 11]. Colleges also participate in the development of health systems and the healthcare environment in general, as medical education is defined as 'the art and science of training doctors who can practice safely in the society and work with partners to create a suitable environment for the work of those graduates' [12].

Another part of the contract is implicit, and relates to fostering the development of the society through different activities, such as students' extracurricular activities, the public service activities of faculty members, and the creation of job opportunities for members of the society.

What is mentioned above does not mean that the establishment of medical colleges is the only solution to a society's development, as establishment in itself requires preparation and adequate resources $[7,13,14]$. These can include: 
1. The presence of hospitals and health centers that provide the minimum level of clinical training with a plan to provide advanced training if needed (the goal here is not only buildings but also the number and appropriateness of cases for training, taking into consideration that some practical training may need to be conducted in other social institutions, like social affairs institutions, depending on the type of curriculum being used).

2. The presence of a working and living environment that facilitates the recruitment of the minimum number of permanent faculty members to create an acceptable ratio of faculty members to students (not everyone who teaches at a college is considered as a permanent faculty member, as there are also adjunct faculty members and visiting faculty members who affect the ratio of teachers to students).

3. Administration, governance (including the nature of the relationship with the university administration) and a faculty development plan.

4. A curriculum that is appropriate to the nature and purpose of establishing the college (one of the most dangerous things a medical college can do is adopt another college's curriculum as it is).

5. Support staff and services.

6. Other educational resources (laboratories, libraries, dissection rooms, clinical skills/simulation laboratories, etc.)

7. Student recruitment plan: being aware of the faculty-student ratio, learning resources and places of residence.

Some colleges in Sudan were established without a complete study plan. However, these colleges have students, faculty, employees and workers, and the society in which they operate has benefited from the presence of the college in many ways, including new job opportunities and the provision of health and medical services. The most important thing to consider is that these colleges may produce much-needed new doctors, after all the doctor to population ration in Sudan remains small, especially with regards to the general health coverage goal of 2030 [15]. However, it is crucial that a high level of quality in all the colleges is ensured so that their outputs satisfy society's health needs.

\section{Collegectomy or not?}

This paper proposes a balance between quality and society's needs by asking that each college be taken as a separate case instead of making a collective decision. It is necessary to consider all the educational and social aspects related to the college to avoid doubly penalizing the societies in which these colleges operate: both by opening 
the college in the first place without the necessary study plans, and then by making a decision regarding its closure without carrying out the appropriate studies.

Based on successful practices in medical education worldwide, some of the decisions may be made using the following list:

1. College support. Here, support is not limited to financial but to any other form of support including that pertaining to the faculty and the curriculum.

2. Changing the college strategy. This can be done by adopting social accountability, a solution that several other countries such as South Africa, Canada, the Philippines and Australia have used to increase the effectiveness of their medical colleges [16-19].

3. Modifying the curriculum. This can be done by following the step-ladder curriculum, which is one of the solutions which the Philippines has used to establish medical colleges in remote places [20,21]. Society-based clinical training could also be implemented - it is currently practiced in certain Canadian colleges [22]. Finally, adopting inter-professional education to maximize the effectiveness of graduates should be considered [23].

4. Integrating medical colleges. Colleges could be encouraged to work together and share experiences and learning resources using a schedule to work toward independence; Canada and Iran have implemented this [17, 24].

5. Collegectomy. If no other option can be applied, a Flexnerian-era collegectomy becomes a viable option [25].

6. Any other solution that fits the Sudanese context.

A common but discouraged practice is to transfer students from one college to another college; this has adverse effects on the host college's students by increasing the proportion of students to faculty and heightening the academic burden on the faculty members and the hosting college's students. It also has future adverse effects on the guest students, as it reduces their association with their college and the society of that college. In short, it may negatively impact and even undermine the goal of establishing the college in the first place.

Many stakeholders, especially those on social media platforms, are calling for the closure of the so-called 'new' medical colleges ('collegectomies'). However, this paper argues that what should drive the decision-making regarding collegectomy is Sudan's medical council (SMC), which has a well-structured process and standards for accrediting medical schools. It is important to support SMC in this regard, which can be done with political empowerment and the necessary financial resources as part of a national plan to improve the quality of medical education in Sudan featuring collaboration between all stakeholders. 


\section{Conclusion}

This communication suggests a balance between quality in Medical Education in Sudan and the society's health and health-related needs; it explores international experiences that can be adapted to the Sudanese medical education sector, allowing for the consideration of each College as a separate case. Closing colleagues (Collegectomy) is not the only solution.

\section{References}

[1] Fahal AH (2007). Medical education in the Sudan: its strengths and weaknesses. Medical Teacher. 29(9): 910-914.

[2] Al Sadig Al Mahdi T (2019). Overview of the course of undergraduate medical education in the Sudan. Sudan Journal of Medical Sciences. 14(4): 188-201.

[3] Ahmed AM (2012). Medical education in Sudan: emerging issues and acute needs. Sudanese Journal of Public Health. 7: 2.

[4] Tekian A, Almazrooa AA (2011). Does Saudi Arabia need an Abraham Flexner? Medical Teacher. 33(1): 72-73.

[5] Benor DE (2014). A new paradigm is needed for medical education in the midtwenty-first century and beyond: are we ready? Rambam Maimonides Medical Journal. 5(3): e0018.

[6] Abdulrahman K. Bin (2011). Saudi Arabia does not need an Abraham Flexner. Medical Teacher. 33(1): 74-75.

[7] Sjöström H, Christensen L, Nystrup J et al. (2019). Quality assurance of medical education: lessons learned from use and analysis of the WFME global standards. Medical Teacher. 14(6): 1-6.

[8] Hays R (2007). Community-oriented medical education. Teaching and Teacher Education. 23(3): 286-293.

[9] Păunescu C, Drăgan D, Găucă O. (2017). Examining obligations to society for QS Stars best ranked universities in social responsibility. Management \& Marketing. 12(4): 551-570.

[10] Budhathoki SS, Zwanikken PAC, Pokharel PK et al. (2017). Factors influencing medical students' motivation to practise in rural areas in low-income and middleincome countries: a systematic review. BMJ Open. 7(2): e013501. 
[11] Techakehakij W, Arora R (2017). Rural retention of new medical graduates from the Collaborative Project to Increase Production of Rural Doctors (CPIRD): a 12-year retrospective study. Health Policy and Planning. 32(6): 809-815.

[12] Boelen C (2018). Coordinating medical education and health care systems: the power of the social accountability approach. Medical Education. 52(1): 96-102.

[13] Hays RB, Strasser RP, Sen Gupta TK (2019). Twelve tips for establishing a new medical school. Medical Teacher. pp. 1-5. DOI: 10.1080/0142159X.2019.1571570

[14] World-Federation-for-Medical-Education. Criteria for a new medical school [Internet]. Criteria for Establishment of a New Medical School. 2016 [cited 2020 Jan 21]. Available from: https://wfme.org/home/projects/criteria-for-a-new-medicalschool/

[15] WHO (2019). Global status report on alcohol and health 2018.

[16] Murray RB, Larkins S, Russell H et al. (2012). Medical schools as agents of change: socially accountable medical education. Medical Journal of Australia. 196(10): 653.

[17] Strasser R, Hogenbirk JC, Minore B et al. (2013). Transforming health professional education through social accountability: Canada's Northern Ontario School of Medicine. Medical Teacher. 35(6): 490-496.

[18] Kwizera EN, Iputo JE (2011). Addressing social responsibility in medical education: the African way. Medical Teacher. 33(8): 649-653.

[19] Woollard B, Boelen C (2012). Seeking impact of medical schools on health: meeting the challenges of social accountability. Medical Education. 46(1): 21-27.

[20] Borrinaga RO, Tantuico-Koh I (1995). The roles of the UP Manila-School of Health Sciences (UPM-SHS) in health sector reform in the Philippines. In: Regional Conference on Health Sector Reform in Asia.

[21] Siega-Sur JL, Woolley T, Ross SJ et al. (2017). The impact of socially-accountable, community-engaged medical education on graduates in the Central Philippines: implications for the global rural medical workforce. Medical Teacher. 39(10): 1084-1091.

[22] McGregor MJ, Sloan J (2014). Realigning training with need: a case for mandatory family medicine resident experience in community-based care of the frail elderly. Canadian Family Physician. 60(8): 697-699.

[23] Barr H, Koppel I, Reeves S et al. (2008). Effective interprofessional education: argument, assumption and evidence (promoting partnership for health). John Wiley \& Sons.

[24] Tresilian F (1997). The reform of medical education in Iran. The BMJ. 1(3032): 172.

[25] Cooke M, Irby DM, Sullivan W et al. (2006). American medical education 100 years after the Flexner report. The New England Journal of Medicine. 355(13): 1339-1344. 